\title{
Effect of different conservation methods on some mechanical properties of swine bone
}

\author{
G. Szebényi ${ }^{1,2}$, P. Görög ${ }^{3}$, Á. Török ${ }^{3}$ \& R. M. Kiss ${ }^{2,4}$ \\ ${ }^{1}$ Budapest University of Technology and Economics, \\ Department of Polymer Engineering, Hungary \\ ${ }^{2}$ Budapest University of Technology and Economics, \\ Cooperation Research Center for Biomechanics, Hungary \\ ${ }^{3}$ Budapest University of Technology and Economics, Department of \\ Construction Materials and Engineering Geology, Hungary \\ ${ }^{4}$ Budapest University of Technology and Economics, \\ Department of Structural Engineering, Hungary
}

\begin{abstract}
In the development of new strategies for different spine fixation methods, new methods must be tested biomechanically under in vitro conditions before clinical trials can be performed. The effect of different conservation mode on the mechanical properties of vertebrae is an important question. The aim of our research was to determine the effects of three different conservation methods (fresh, no conservation - F; fresh-frozen - FF, alcohol-glycerin-fixation - AG; cooling-storage - CS). 100 swine vertebrae (Th4-Th8) were dimidiated into two specimens. These 200 specimens were assigned to four different groups. After conservation, the Young modulus and compressive strength were determined and compared to the same properties of fresh specimens. After 48-hour cooling the Young modulus and the compressive strength decreased by 39\%. After 27-day freezing the Young modulus and the compressive strength decreased by $5 \%$. After 27-day storage in ethyl-alcohol the Young modulus decreased by $12 \%$ and the compressive strength increased by $57 \%$. The different conservation methods significantly influenced the mechanical properties of swine vertebrae. Mechanical properties were influenced less by frozen storage, so this type of storage is recommended for the conservation of vertebrae.
\end{abstract}

Keywords: conservation method, vertebrae, compressive strength, young modulus. 


\section{Introduction}

Degenerative spine diseases represent an increasing proportion in orthopaedic deformations. In many cases, they are caused by the osteoporosis of the vertebral body or the degeneration of the intervertebral disk. If the degeneration has not yet progressed, it is usually sufficient to apply conservative treatment; if the spine segment (consisting of two neighbouring vertebrae and the intervertebral disk in between, together with the osseous vertebral processes and the surrounding ligaments and muscles) becomes instable, surgical treatment will be necessary. Precise knowledge of mechanical properties of vertebrae is important for the numerical modelling of osteoporosis and the impact of various surgical interventions, on the one hand, and for scheduling different surgical methods. The efficiency of each new surgical method must be demonstrated by tests performed on in vitro specimens before introduction.

First of all, this raises the issue of differences between the mechanical properties of living and dead vertebrae. This issue is complicated by the fact that diverse storage (conservation) methods have different impacts on the mechanical properties of vertebrae. The question can also be posed as follows: how should vertebral bodies be preserved for the in vitro examination of different surgical techniques in order that their mechanical properties resemble the characteristics of live vertebral bodies the most.

Fitzgerald [1, 2] stated that the mechanical properties of bones and ligaments change significantly 5 hours post mortem this particularly applies to tensile strengths. Linde and Sorensen [3] measured significant decreases in the Young's modulus 24 hours post mortem by compressive tests on trabecular bones extracted from the tibia.

There are two recommended methods for storage to identify strength characteristics: cooling and freezing. Both methods of storage can be dry or wet (in a physiological saline solution). In the case of cooling, samples must be stored at $+5 \mathrm{C}^{\circ}$, and in the case of freezing they must be stored at $-20 \mathrm{C}^{\circ}$. In the case of storage by freezing, samples must be defrosted at $+5 \mathrm{C}^{\circ} 24$ hours before the strength tests are performed. In the case of storage by freezing, the mechanical properties of human and animal bones and ligaments do not change significantly even after 100 days of storage [4-9]. A major drawback of this storage method is that it fails to kill bacteria and pathogenic germs. On the one hand, this is dangerous for the person carrying out the experiment; on the other hand, it may change mechanical properties significantly [9].

Some sort of chemical solution is generally used for the storage and disinfection of samples to be used for biomechanical and mechanical tests (to kill pathogenic germs). The oldest and most widespread method of storage is the storage in formaldehyde. Formaldehyde kills bacteria, viral and other nonbacterial pathogens rapidly and surely, and it is a very strong disinfectant [9]. It was assumed that formaldehyde enters into a reaction with collagen fibres and thereby alters the mechanical properties of bones, particularly in terms of the capability of energy absorption [10, 11]. van Haaren et al. [12] found that the Young's modulus of large bones extracted from goats changes significantly only 
after one year of storage in formaldehyde. Measurements by Öhman et al. [13] show that 8 weeks of storage in formaldehyde does not change the hardness and compressive strength of human cortical bones, but it decreases the Young's modulus measured by compression. Unger et al. [9] found that following 6 months of storage of cortical bones removed from human tibia and bovine femur in formaldehyde, the Young's modulus, the flexural strength, and the energy absorption do not change, but the plastic energy absorption is significantly decreased.

Another widespread storage agent is ethyl-alcohol with an excellent bactericidal effect and favourable hygroscopic properties [9]. Sedlin [8] stored human femur cortical bones in $40 \mathrm{~m} \%$ ethyl-alcohol for a short time and measured a 2.5-4\% decrease in the Young's modulus associated with pressure. Linde and Sorensen [3] stated after 100 days of storage in $70 \mathrm{~m} \%$ ethyl-alcohol that the Young's modulus and the elastic energy absorption increase, though not significantly, in the case of trabecular bones extracted from human tibia. Unger et al. [9] stored cortical bones extracted from bovine femur in $96 \mathrm{~m} \%$ ethylalcohol (3 m\% glycerine and $1 \mathrm{~m} \%$ phenol) for 6 months. They established by way of a three-point bending test that the Young's modulus does not change, the flexural strength and the elastic energy absorption increase significantly, while the plastic energy absorption significantly decreases. In the case of rat bones, no significant discrepancies were found in compressive strength and the Young's modulus [4].

No data were found in the literature on the comparison of the mechanical properties of human or animal vertebrae in the case of different storage methods. The objective of this research was to find out about the influence of various short-term (maximum 27-day) storage methods (cooling for 48 hours, storage in $96 \mathrm{~m} \%$ ethyl-alcohol for 27 days and freezing at $-20 \mathrm{C}^{\circ}$ for 27 days) on strength properties compared to the strength characteristics of fresh samples of vertebrae of swine.

\section{Material and method}

\subsection{Samples}

One of the options to produce samples is by boring out cylinders of $3 \mathrm{~mm}$ diameter and $30 \mathrm{~mm}$ height from the vertebral bodies and to carry out compressive strength tests on them [13]. The disadvantages of this type of test are that samples are shaped, and that four samples cannot be extracted from one vertebral body.

Another option is to determine strength characteristics on complete vertebral bodies [14]. The drawback of this method is that the mechanical properties of different vertebrae of the same individual or those of the vertebrae of the same level of different individuals can be compared to each other.

In order to avoid these problems, the vertebral bodies subjected to the tests were halved (fig. 1) and the one and the other half of the vertebral body were stored in a different manner. This made it possible to examine the effect of storage (preservation) method on the same vertebra. 


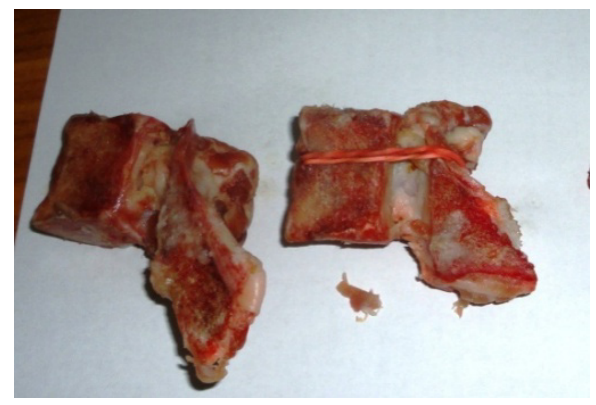

Figure 1: Bisected vertebral body before the compressive test.

Thoracic vertebrae 4, 5, 6, 7, 8 of 19-month-old mangalica swine were used for the tests after removing all soft tissues therefrom. 100 vertebrae were included in the tests, 20 of each in equal proportions.

\subsection{Storage of vertebrae}

After the animal was killed, vertebrae were stored at $+7 \mathrm{C}^{\circ}$ for 3 hours; processing (excision of vertebrae, removal of soft tissues, bisection) and transport were carried out at this temperature. Vertebrae were marked by coloured rubber bands and the area of the closing plate was determined. Half vertebrae were divided into four groups according to the method of storage:

- the first group consisted of vertebrae broken fresh; compression tests were performed on them at room temperature (fresh breakage) after 3 hours of processing and transport;

- $\quad$ in the case of the second group, vertebrae were stored dry in sealed plastic bags at $+5 \mathrm{C}^{\circ}$ for 48 hours to be followed by the compression test at room temperature;

- $\quad$ in the case of the third group, vertebrae were stored dry in sealed plastic bags at $-20 \mathrm{C}^{\circ}$ for 27 days; they were defrosted at $+8 \mathrm{C}^{\circ} 12$ hours before testing and the compression test was performed at room temperature afterwards;

- $\quad$ in the case of the fourth group, vertebrae were stored in $96 \mathrm{~m} \%$ ethylalcohol ( $3 \mathrm{~m} \%$ glycerine and $1 \mathrm{~m} \%$ phenol) at $+15 \mathrm{C}^{\circ}$ for 27 days; the compression test was performed at room temperature.

Table 1 summarizes the storage methods of vertebrae.

Table 1: $\quad$ Storage (preservation) method of vertebrae.

\begin{tabular}{|l|l|l|}
\hline Sign of vertebrae & \multicolumn{2}{|c|}{ Storage method } \\
\hline & left half & right half \\
\hline Th4 & broken fresh & stored in alcohol \\
\hline Th5 & broken fresh & frozen \\
\hline Th6 & cooled & frozen \\
\hline Th7 & broken fresh & cooled \\
\hline Th8 & cooled & stored in alcohol \\
\hline
\end{tabular}




\subsection{Compression test method}

Compression tests were carried out at the Central Laboratory of the Biomechanical Cooperation Research Centre of BUTE, on an Instron 8872 servo-hydraulic device. Samples were fastened by a fixed clamp on one side and a hinged clamp on the other side. Vertebrae were placed so that load should be transferred directly along the vertebral body (fig. 2). In the course of the tests, samples were pre-loaded by a force of $50 \mathrm{~N}$ at a $2 \mathrm{~mm} / \mathrm{min}$ crosshead speed. During the measurement, the crosshead speed continued to be $2 \mathrm{~mm} / \mathrm{min}$. In the case of each measurement, the measurement control software recorded crosshead displacement and the force exerted by the hydraulic measuring tube through a 32-bit dynamometer cell of $25 \mathrm{kN}$ maximum loadability. Data were processed to determine the initial Young's modulus, the force associated with $5 \mathrm{~mm}$ crosshead displacement and the maximum force. In the knowledge of the area of the closing plate, the stress associated with $5 \mathrm{~mm}$ crosshead displacement and the maximum force were calculated.

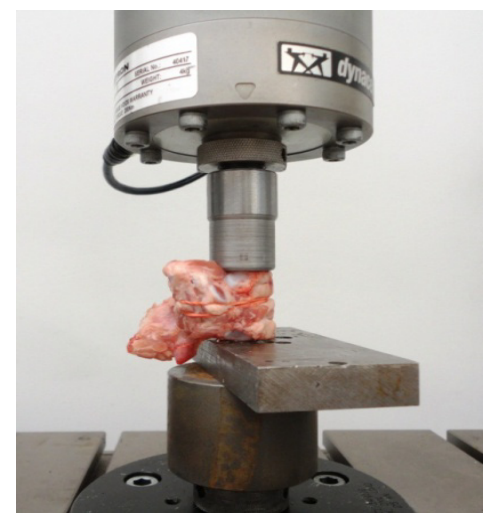

Figure 2: $\quad$ Compression test.

\subsection{Statistical processing}

20 vertebrae were available in each group. Group mean and standard deviation were calculated from the results of each 20 vertebrae. In the case of half vertebra pairs stored differently, results were compared by one-sample T-tests applying a symmetrical critical range.

\section{Results}

The test results are summarized in table 2, grouped according to the method of storage. 
Table 2: Mechanical properties of the vertebral bodies examined in the case of different storage methods.

\begin{tabular}{|l|l|c|c|c|c|}
\hline \multicolumn{1}{|c|}{ Storage } & \multicolumn{1}{|c|}{$\begin{array}{c}\text { Sign of } \\
\text { vertebrae }\end{array}$} & Area $\mathbf{( m m}^{2} \mathbf{)}$ & $\begin{array}{c}\boldsymbol{E}_{\text {initial }} \\
\mathbf{( M P a )}\end{array}$ & $\begin{array}{c}\sigma_{5 \mathbf{m m}} \\
\mathbf{( M P a )}\end{array}$ & $\begin{array}{c}\sigma_{\max } \\
\mathbf{( M P a})\end{array}$ \\
\hline \multirow{3}{*}{ fresh } & Th4-left & $263.8 \pm 23.2$ & $179 \pm 18$ & $5.8 \pm 1.8$ & $15.6 \pm 6.7$ \\
\cline { 2 - 6 } & Th5-left & $288.1 \pm 21.4$ & $183 \pm 23$ & $6.7 \pm 2.1$ & $16.8 \pm 6.1$ \\
\cline { 2 - 6 } & Th7-left & $304.4 \pm 29.5$ & $144 \pm 14$ & $4.4 \pm 1.3$ & $12.8 \pm 7.1$ \\
\hline \multirow{3}{*}{ cooled } & Th6-left & $291.6 \pm 27.4$ & $124 \pm 21$ & $3.3 \pm 1.5$ & $8.2 \pm 4.4$ \\
\cline { 2 - 6 } & Th7-right & $314.8 \pm 25.4$ & $112 \pm 17$ & $2.7 \pm 1.8$ & $7.8 \pm 5.8$ \\
\cline { 2 - 6 } frozen & Th8-left & $354.9 \pm 27.4$ & $136 \pm 21$ & $3.7 \pm 2.1$ & $8.5 \pm 3.5$ \\
\hline \multirow{2}{*}{$\begin{array}{l}\text { stored in } \\
\text { ethyl-alcohol }\end{array}$} & Th5-right & $279.5 \pm 19.4$ & $174 \pm 28$ & $5.8 \pm 3.4$ & $15.9 \pm 6.8$ \\
\cline { 2 - 6 } & Th6-right & $287.6 \pm 27.4$ & $132 \pm 25$ & $2.9 \pm 1.7$ & $7.9 \pm 3.9$ \\
\cline { 2 - 6 } & Th4-right & $251.4 \pm 28.7$ & $157 \pm 21$ & $8.7 \pm 2.4$ & $24.5 \pm 5.4$ \\
\hline \multirow{2}{*}{ Th8-right } & $370.4 \pm 31.5$ & $106 \pm 14$ & $14.7 \pm 2.9$ & $29.4 \pm 6.4$ \\
\hline
\end{tabular}

Note: $E_{\text {initial }}$ : initial Young's modulus, $\sigma_{5 \mathrm{~mm}}$ : stress associated with $5 \mathrm{~mm}$ crosshead displacement, $\sigma_{\text {max }}$ : stress calculated from maximum force

Based on the results (table 2) it can be stated that compared to the strength characteristics of fresh vertebrae only cooled during processing,

- $\quad$ as a result of 48 hours of cooling, the Young's modulus was reduced by $28 \%$, the stress associated with $5 \mathrm{~mm}$ crosshead displacement by $38 \%$, and the maximum stress by $39 \%$; moreover, there was a significant difference between the strength characteristics of vertebrae stored in the two different manners $\left(\mathrm{p}_{\mathrm{E}}=0.02 ; \mathrm{p}_{\sigma 5}=0.03\right.$; $\left.\mathrm{p}_{\sigma \max }=0.009\right)$;

- $\quad$ as a result of 27 days of freezing, the Young's modulus was reduced by $5 \%$, the stress associated with $5 \mathrm{~mm}$ crosshead displacement by $14 \%$, and the maximum stress by and 5\%; moreover, there was no significant difference between the strength characteristics of vertebrae stored in the two different manners ( $\mathrm{p}_{\mathrm{E}}=0.07 ; \mathrm{p}_{\sigma 5}=0.06$; $\mathrm{p}_{\sigma \max }=0.11$ );

- $\quad$ as a result of 27 days of storage in $96 \mathrm{~m} \%$ ethyl-alcohol, the Young's modulus was reduced by $12 \%$, the stress associated with $5 \mathrm{~mm}$ crosshead displacement was increased by $49 \%$ and the maximum stress by $57 \%$; moreover, there was a significant difference between the strength characteristics of vertebrae stored in the two different manners $\left(\mathrm{p}_{\mathrm{E}}=0.03 ; \mathrm{p}_{\sigma 5}=0.007 ; \mathrm{p}_{\sigma \max }=0.004\right)$.

Compared to the strength characteristics of vertebrae stored cooled for 48 hours (table 2):

- $\quad$ as a result of 27 days of freezing, the Young's modulus was increased by $6 \%$, the stress associated with $5 \mathrm{~mm}$ crosshead displacement was reduced by $12 \%$ and the maximum stress by $4 \%$; moreover, there was no significant difference between the strength characteristics of vertebrae stored in the two different manners $\left(p_{E}=0.09 ; p_{\sigma 5}=0.07\right.$; $\left.\mathrm{p}_{\sigma \max }=0.13\right)$; 
- as a result of 27 days of storage in $96 \mathrm{~m} \%$ ethyl-alcohol, the Young's modulus was reduced by $22 \%$, the stress associated with $5 \mathrm{~mm}$ crosshead displacement was increased by $297 \%$ and the maximum stress by $245 \%$ and the difference is also significant $\left(\mathrm{p}_{\mathrm{E}}=0.01\right.$; $\left.\mathrm{p}_{\sigma 5}=0.0002 ; \mathrm{P}_{\text {omax }}=0.00008\right)$.

\section{Conclusion}

According to the literature, changes in the Young's modulus, strength and the energy absorption were analysed for various storage methods (formaldehyde, ethyl-alcohol, freezing, cooling) by compression and bending tests in the case of cortical and trabecular bones [3, 4, 8, 9, 13]. Tests showed that strength characteristics are affected by different storage methods, but substantial discrepancies can only be observed in the case of long-term storage $[3,4,8,9,13]$.

However, no results or statements were found in the literature as regards the analysis of changes in the strength characteristics of vertebral bodies in the case of different storage (preservation) methods. This can be probably attributed to the fact that the strength characteristics of vertebrae change even within the same individual and significant differences can be observed between individuals, meaning that comparison is difficult. In order to ward this off, bisected vertebrae were examined (fig. 1). Tests have shown that bisected vertebrae can be subjected to compression tests with appropriate attention and preparation.

Tests were performed on swine vertebrae, by reason of the easy availability of samples, on the one hand, and the better repeatability of tests on the other hand. The impact of age, gender and osteoporosis is lower in the case of young swine than in the case of human individuals. In the case of swine's vertebrae, strength differences between various vertebrae can also be better excluded. Presumably, the experimental method tried and tested on swine's vertebrae can be repeated on human vertebrae as well.

In our test series, the impact of various storage methods was compared to fresh vertebrae and vertebrae cooled for 48 hours. Based on the comparison of storage methods, it can be stated that mechanical properties are changed by storage (table 2) compared to the mechanical properties of fresh vertebrae (following 3 hours of storage). Results show that in the case of storage by freezing, there are no significant changes in mechanical properties. Mechanical properties are changed significantly by 48 hours of cooled storage and by storage in ethyl-alcohol. On the basis thereof, the conclusion can also be drawn that the impact of storage should be compared to the results of fresh vertebrae and vertebrae stored by freezing. This corresponds to the recommendation by Unger et al. [9].

Storage en $96 \mathrm{~m} \%$ ethyl-alcohol changes mechanical properties. The Young's modulus is reduced significantly, in agreement with Sedlin's [8] statement, who stored cortical bones in $40 \mathrm{~m} \%$ ethyl-alcohol for 5-10 days. This examination method resembles our testing procedure the most. Beupied et al. [4] measured (non-significant) increases in the Young's modulus of bones determined by 
stretching rat bones Unger et al. [9] by bending human and bovine bones. Discrepancies may be explained by the fact that the Young's modulus measured in the course of the latter two research projects pertains to stretching, while our tests were compression tests performed after short-term storage. The compressive strength increased significantly, corresponding to the statement by Unger et al. [9] on their flexural strength. Increased strength can probably be attributed to the fact that bones are dehydrated as a consequence of storage in ethyl-alcohol [9].

In summary, comparative tests performed using a large number of samples show that the most favourable storage method is storage by freezing as mechanical properties are not changed significantly compared to the mechanical properties of vertebrae broken fresh. It is expedient to opt for this storage method even in the case of short-term storage, although there are no significant differences between the mechanical properties of vertebrae stored cooled for 48 hours and vertebrae stored frozen for one month.

\section{Acknowledgement}

This research has been supported by OTKA project K075018.

\section{References}

[1] Fitzgerald, E.R., Dynamic mechanical measurements during the life to death transition in animal tissues. Biorheology, 12, pp. 397-408, 1975.

[2] Fitzgerald, E.R., Postmortem transition in the dynamic mechanical properties of bone. Med Phys, 4, pp. 49-53, 1977.

[3] Linde, F. and Sorensen, H.C.F., The effect of different storage methods on the mechanical properties of trabecular bone. Journal of Biomechanics, 26, pp. 1249-1252, 1993.

[4] Beaupied, H., Dupuis, A., Arlettaz, A., Brunet-Imbault, B., Bonnet, N., Jaffre, C., Benhamou, C.L. and Courteix, D., The mode of bone conservation does not affect the architecture and the tensile properties of rat femur. Biomedical Materials and Engineering, 16, pp. 253-259, 2006.

[5] Panjabi, M.M., Krag, M., Summers, D. and Videman, T., Biomechanical time-tolerance of fresh cadaveric human spine specimens. J Orthop Res, 3, pp. 292-300, 1985.

[6] Pelker, R.R., Friedlaender, G.E., Markham, T.C., Panjabi, M.M. and Moen, C.J., Effects of freezing and freeze-drying on the biomechanical properties of rat bone. J Orthop Res, 1, pp. 405-411, 1984.

[7] Sedlin, E.D. and Hirsch, C., Factors affecting the determination of the physical properties of femoral cortical bone. Acta Orthop Scan, 37, pp. 2948, 1966.

[8] Sedlin, E.D., A rheologic model for cortical bone: A study of the physical properties of human femoral samples. Acta Orthop Scan, S83, pp. S1-S77, 1965. 
[9] Unger, S., Blauth, M. and Schmoelz, W., Effects of three different preservation methods on the mechanical properties of human and bovine cortical bone. Bone, 47, pp. 1048-1053, 2010.

[10] Currey, J.D., Brear, K., Zioupos, P. and Reilly, G.C., Effect of formaldehyde fixation on some mechanical properties of bovine bone. Biomaterials, 16, pp. 1267-1271, 1995.

[11] Goh, J.C., Anf, E.J. and Bode, K. Effect of preservation medium on the mechanical properties of cat bones. Acta Orthop Scan, 60, pp. 465-467, 1989.

[12] van Haaren, E.H, van der Zward, B.C., van der Veen, A.J., Heyligers, I.S., Wuisman, P.I. and Smit, T.H., Effect of long-term preservation on the mechanical properties of cortical bone in goats. Acta Orthop, 79, pp. 708716, 2008.

[13] Öhman, C., Dall’Ara, E., Beleani, M., van Sint Jan, S. and Viceconti, M., The effects of embalming using a $4 \%$ formalin solution on the compressive mechanical properties of human cortical bone. Clinical Biomechanics, 23, pp. 1294-1298, 2008.

[14] Kulcsár, Zs., Szebényi, G., Kiss, R.M., Marosfői, M., Borbás, L. and Szikora, I., Perkután csontcements csigolyaplasztika hatása a szomszédos csigolyatestekre: előzetes biomechanikai vizsgálat (Effect of percutaneous vertebroplasty on adjacent vertebrae: a preliminary biomechanical study). Biomechanica Hungarica, 2, pp. 19-25, 2010. 